Check for updates

Cite this: RSC Adv., 2019, 9, 34691

Received 20th March 2019

Accepted 21st October 2019

DOI: 10.1039/c9ra02161b

rsc.li/rsc-advances

\section{A bromine-catalysis-synthesized poly(3,4- ethylenedioxythiophene)/graphitic carbon nitride electrochemical sensor for heavy metal ion determination $\dagger$}

\begin{abstract}
Wei Wu, ${ }^{a b}$ Ahmat Ali, ${ }^{a b}$ Ruxangul Jamal, ${ }^{\text {ab }}$ Mihray Abdulla, ${ }^{\text {ab }}$ Tursunnisahan Bakriab and Tursun Abdiryim (D) *ab

In this paper, poly(3,4-ethylenedioxythiophene)/graphitic carbon nitride (PEDOT/g- $\mathrm{C}_{3} \mathrm{~N}_{4}$ ) composites were prepared by the bromine catalysed polymerization (BCP) method with varying weight ratios of monomer to $\mathrm{g}-\mathrm{C}_{3} \mathrm{~N}_{4}$. For comparison, solid-state polymerization (SSP) and metal oxidative polymerization (MOP) methods were also used for the synthesis of PEDOT/g- $\mathrm{C}_{3} \mathrm{~N}_{4}$ composites. Electrochemical determination of heavy metal ions $\left(\mathrm{Cd}^{2+}\right.$ and $\left.\mathrm{Pb}^{2+}\right)$ was carried out by differential pulse voltammetry (DPV) on composite-modified glass carbon electrodes (GCEs), which were prepared by different methods. The obtained composites were analysed by Fourier transform infrared spectroscopy (FT-IR), ultraviolet-visible absorption spectroscopy (UV-vis), X-ray diffraction (XRD), energy-dispersive X-ray spectroscopy (EDS), scanning electron microscopy (SEM), and transmission electron microscopy (TEM). The results showed that the bromine catalysed polymerization (BCP) method is an effective way to prepare the PEDOT/g$\mathrm{C}_{3} \mathrm{~N}_{4}$ composite, and the combination of PEDOT with $\mathrm{g}-\mathrm{C}_{3} \mathrm{~N}_{4}$ can improve the electrochemical activity of electrode materials. And, the composite from the BCP method modified electrode (PEDOT/10 wt\% g$\mathrm{C}_{3} \mathrm{~N}_{4} / \mathrm{GCE}$ ) exhibited the widest linear responses for $\mathrm{Cd}^{2+}$ and $\mathrm{Pb}^{2+}$, ranging from $0.06-12 \mu \mathrm{M}$ and 0.04-11.6 $\mu \mathrm{M}$ with detection limits $(\mathrm{S} / \mathrm{N}=3)$ of $0.0014 \mu \mathrm{M}$ and $0.00421 \mu \mathrm{M}$, respectively.
\end{abstract}

\section{Introduction}

Conducting polymers (CPs), such as polyaniline (PANI), polypyrene (PPy) and poly(3,4-ethylenedioxythiophene) (PEDOT), have been prevalent in the field of photoelectric materials for several decades since they were first discovered by Shirakawa et $a{ }^{1-3}$ PEDOT is one of the most widely used conductive polymers due to its good electrochemical stability and high electrical conductivity. ${ }^{4}$ Since Leverkusen Bayer first synthesized this compound in 1988, much research has been done on PEDOT. Due to its unique $\pi$-conjugation system, high conductivity, easy processing and film formation, PEDOT has been used in many applications, such as energy storage, ${ }^{5,6}$ electrochromic devices, ${ }^{7}$ ion sensing ${ }^{8}$ and biosensors. ${ }^{9}$ In general, PEDOT is not used alone but is compounded with other materials such as metals, ${ }^{10}$ metal oxides, ${ }^{11,12}$ and carbon materials. ${ }^{13,14}$

${ }^{a}$ Key Laboratory of Oil and Gas Fine Chemicals, Ministry of Education, Xinjiang Uygur Autonomous Region, Xinjiang University, Urumqi, 830046, P. R. China. E-mail: tursunabdir@sina.com.cn; jruxangul@sina.com

${ }^{b}$ Key Laboratory of Functional Polymers, Xinjiang University, Urumqi 830046, People's Republic of China

$\dagger$ Electronic supplementary information (ESI) available. See DOI: 10.1039/c9ra02161b
Carbon-based materials typically include carbon nanotubes, single-wall carbon nanohorns, bucky papers, graphene, and fullerenes. ${ }^{15}$ New features of carbon materials increase the wide variability of multifunctional carbon-based sensing electrodes that exhibit high sensitivity and low sensing limits for a variety of chemical and biological analytes due to the extraordinary specific surface area, electrical conductivity, chemical durability, biocompatibility and mechanical strength of carbonbased materials. ${ }^{16-19}$ Graphene-like two-dimensional nanomaterials have been extensively studied for electrochemical sensing applications due to their structural properties similar to those of graphene and tuneable bandgap capability, ${ }^{20}$ such as transition metal dichalcogenides, ${ }^{21,22}$ hexagonal boron nitride nanosheets, ${ }^{23,24}$ and graphitic carbon nitride $\left(\mathrm{g}-\mathrm{C}_{3} \mathrm{~N}_{4}\right)$ nanosheets. ${ }^{25-27}$ Among these, g- $\mathrm{C}_{3} \mathrm{~N}_{4}$ has attracted massive attention due to its simple synthesis, satisfactory catalytic activity, excellent chemical stability and environmental friendliness. According to reports, the strong electron donor properties of nitrogen can affect the electronic structure and result in different activity-enhancing mechanisms. ${ }^{20}$ In addition, g- $\mathrm{C}_{3} \mathrm{~N}_{4}$ ultrathin sheets demonstrate a strong affinity towards heavy metal ions due to the intrinsic $-\mathrm{NH}$ and $-\mathrm{NH}_{2}$ groups of $\mathrm{g}-\mathrm{C}_{3} \mathrm{~N}_{4}$, and this affinity is very beneficial for metal ions detection. ${ }^{28}$ However, the mediocre electroconductivity of $\mathrm{g}-\mathrm{C}_{3} \mathrm{~N}_{4}$ seriously 
affects its application in reality. ${ }^{27,29-31}$ Therefore, modifying it by compounding with other materials, such as graphene or CPs, is necessary to enable efficient electron transfer.

Recently, a number of PEDOT/g- $\mathrm{C}_{3} \mathrm{~N}_{4}$ composites have been synthesized for studies on supercapacitors, biosensors, photocatalysis and catalytic hydrogen production. For example, a g$\mathrm{C}_{3} \mathrm{~N}_{4}$ nanofibre-doped PEDOT-modified electrode was used for the simultaneous determination of ascorbic acid and acetaminophen; ${ }^{32}$ a new type of carbon nitride-based polymer composite was used for enhanced photocatalytic hydrogen production..$^{33,34}$ However, there is no research in the field of heavy metal ion detection. Hence, the preparation of $\mathrm{PEDOT} / \mathrm{g}-\mathrm{C}_{3} \mathrm{~N}_{4}$ nanocomposites is a feasible method for determining heavy metal ions.

In general, the methods employed to prepare polymer-based composites include electrochemical polymerization, ${ }^{35}$ chemical oxidation polymerization, ${ }^{36}$ metal-catalysed coupling, ${ }^{37}$ solidstate polymerization (SSP), ${ }^{38}$ acid-assisted polymerization, ${ }^{39}$ and photoinduced polymerization. ${ }^{40}$ However, polymer-based composites synthesised by SSP often have performance fluctuations due to uneven mixing of the inorganic phase and organic phase. Furthermore, the metals used in the abovementioned chemical polymerization methods are difficult to remove and act as dopants. ${ }^{41}$ For example, $\mathrm{FeCl}_{3}$-catalysed polymerization can result in residual iron, and after several cycles of de-doping, an obvious electron paramagnetic resonance signal and sharp XRD peaks $\left(\mathrm{FeCl}_{4}{ }^{-}\right.$-doping) are still observed. ${ }^{42-46}$ Hence, obtaining a metal-free polymer is essential for improving the performance of devices, such as OLEDs, solar cells and heavy metal ion sensors, because the metal present in the polymer occupies the active sites, which act as quenching sites for excitons. ${ }^{47}$ In summary, the selection of a suitable polymerization method is important for the preparation of polymer composites. Patra et al. reported a metal free bromine catalyzed polymerization for the synthesis of PEDOT and found this method providing metal free and virtually defect free PEDOT under mild reaction conditions. ${ }^{48}$ However, there is no report for preparation of composites with PEDOT by this method.

In this paper, PEDOT/g- $\mathrm{C}_{3} \mathrm{~N}_{4}$ composites were prepared by the bromine catalyzed polymerization (BCP) method with varying weight ratios of monomer to $\mathrm{g}-\mathrm{C}_{3} \mathrm{~N}_{4}$. For comparison, the SSP and metal oxidative polymerization (MOP) methods were also used for the synthesis of PEDOT/g- $\mathrm{C}_{3} \mathrm{~N}_{4}$ composites. And, the composites are used as electrochemical sensors for determination of heavy metal ions $\left(\mathrm{Cd}^{2+}\right.$ and $\left.\mathrm{Pb}^{2+}\right)$. The results showed that among the composites from the bromine catalyzed polymerization method, PEDOT/10 wt $\% \mathrm{~g}-\mathrm{C}_{3} \mathrm{~N}_{4}$ exhibited the widest linear responses and excellent sensitivity for heavy metal ions $\left(\mathrm{Cd}^{2+}\right.$ and $\left.\mathrm{Pb}^{2+}\right)$. Furthermore, compared with the SSP and MOP method composites, the reliability and linear detection range of the composite from the $\mathrm{Br}_{2}$-catalysed polymerization method were significantly improved.

\section{Experimental}

\subsection{Reagents}

3,4-Ethylenedioxythiophene (EDOT) and carbamide were obtained from J\&K Scientific Ltd. $N$-Bromosuccinimide (NBS) and
$\mathrm{Br}_{2}$ were purchased from Aladdin. Anhydrous ethanol, isopropanol, tetrahydrofuran (THF), anhydrous ferric chloride, $\mathrm{CHCl}_{3}$, and $\mathrm{CH}_{3} \mathrm{COONa}$ were purchased from Tianjin ZhiYuan Chemical Reagent Ltd. for use without further purification. The $0.1 \mathrm{~mol} \mathrm{~L}^{-1}$ acetate buffer solution (ABS) was prepared by $0.1 \mathrm{~mol} \mathrm{~L}^{-1}$ sodium acetate and acetic acid, and standard solutions of $0.001 \mathrm{M} \mathrm{Cd}^{2+}$ and $\mathrm{Pb}^{2+}$ were obtained by dissolving $\mathrm{Pb}(\mathrm{AcO})_{2}$ and $\mathrm{Cd}(\mathrm{AcO})_{2}$ in ultrapure water, respectively.

\subsection{Synthesis of $\mathrm{g}-\mathrm{C}_{3} \mathrm{~N}_{4}$}

The $\mathrm{g}-\mathrm{C}_{3} \mathrm{~N}_{4}$ sample was synthesized according to the literature. ${ }^{49}$ First, $10 \mathrm{~g}$ of carbamide was added to a $40 \mathrm{~mL}$ crucible and placed in a muffle furnace. After that, the precipitate was heated to $500{ }^{\circ} \mathrm{C}$ for $2 \mathrm{~h}$ at a rate of $10^{\circ} \mathrm{C}$ per minute, followed by heating to $550{ }^{\circ} \mathrm{C}$ for an additional $2 \mathrm{~h}$. Finally, the crucible was cooled to ambient temperature, and a yellowish solid powder was obtained after washing with absolute ethanol and distilled water.

\subsection{Synthesis of monomer DBEDOT}

DBEDOT was prepared according to a method used in previous research. ${ }^{50,51}$ EDOT $(3.0 \mathrm{~g}, 21.1 \mathrm{mmol})$ was dissolved in a mixture of THF and HAc (200 mL, $1: 1$ by volume). NBS ( $8.6 \mathrm{~g}$, $48.3 \mathrm{mmol}$ ) was added to the mixture. After stirring at room temperature and in the dark for $2 \mathrm{~h}$, a certain amount of ice was added to the solution, and some silvery white crystals appeared. The crystals were then filtered, washed with iced ethanol and dried over a vacuum at room temperature to obtain the pure product (3.9 $\mathrm{g}, 61.7 \%$ yield).

\subsection{Preparation of PEDOT/g- $\mathrm{C}_{3} \mathrm{~N}_{4}$ composites by BCP}

To obtain composites with different contents of $\mathrm{g}-\mathrm{C}_{3} \mathrm{~N}_{4}$, DBEDOT $(0.3 \mathrm{~g}, 1 \mathrm{mmol})$ was added to $20 \mathrm{~mL} \mathrm{CHCl}_{3}$ that had different ratios of $\mathrm{g}-\mathrm{C}_{3} \mathrm{~N}_{4}$ and was ultrasonically dispersed for $20 \mathrm{~min}$. Then, $\mathrm{Br}_{2}(0.64 \mathrm{~g}, 4 \mathrm{mmol})$ solution was added to $\mathrm{CHCl}_{3}$ $(2 \mathrm{~mL})$ at room temperature. Next, the reaction mixture was heat to $50{ }^{\circ} \mathrm{C}$ and stirred for $48 \mathrm{~h}$. After completion of the reaction, a purple-black solid precipitate was obtained. A black solid powder was obtained after washing with acetone and $\mathrm{CHCl}_{3}$. Pure PEDOT was obtained using the same method without adding $\mathrm{g}-\mathrm{C}_{3} \mathrm{~N}_{4}$.

\subsection{Preparation of PEDOT $/ \mathrm{g}-\mathrm{C}_{3} \mathrm{~N}_{4}$ composites by SSP}

A mixture of DBEDOT $(0.3 \mathrm{~g}, 1 \mathrm{mmol})$ and a certain amount of $\mathrm{g}$ $\mathrm{C}_{3} \mathrm{~N}_{4}$ in $10 \mathrm{~mL} \mathrm{CHCl}_{3}$ was ultrasonicated for $20 \mathrm{~min}$. After ultrasonication, the mixture was placed in an agate mortar to completely evaporate the chloroform. Then, the mixture was gently ground for 60 min until the DBEDOT was evenly mixed with $\mathrm{g}-\mathrm{C}_{3} \mathrm{~N}_{4}$; the mixture was kept in a vacuum oven at $60{ }^{\circ} \mathrm{C}$ for $24 \mathrm{~h}$. Finally, the residue was washed with $\mathrm{CHCl}_{3}$ and absolute ethanol and then dried at $60{ }^{\circ} \mathrm{C}$ for $24 \mathrm{~h}$.

\subsection{Preparation of PEDOT/g- $\mathrm{C}_{3} \mathrm{~N}_{4}$ composites by MOP}

First, EDOT ( $0.3 \mathrm{~g}, 1 \mathrm{mmol})$ and a certain amount of $\mathrm{g}-\mathrm{C}_{3} \mathrm{~N}_{4}$ were added to chloroform $(30 \mathrm{~mL})$ and ultrasonically dispersed for $30 \mathrm{~min}$. After ultrasonication, anhydrous ferric chloride (0.65 g, 4 
mmol) was added to the mixture by ultrasonication for an additional $30 \mathrm{~min}$. Then, the reaction was magnetically stirred at room temperature for $24 \mathrm{~h}$. Finally, the reaction product was filtered to give a black solid, which was washed sequentially with chloroform, distilled water and anhydrous ethanol until the filtrate was colourless and then dried under vacuum at $60^{\circ} \mathrm{C}$ for $24 \mathrm{~h}$.

\subsection{Preparation of modified electrodes}

In general, the GCEs were sequentially polished with 1.0, 0.3, and $0.05 \mu \mathrm{m}$ aluminium oxide abrasives and then modified by a simple method. A $5 \mu \mathrm{L}$ aliquot of the PEDOT/g- $\mathrm{C}_{3} \mathrm{~N}_{4}$ suspension $(1 \mathrm{mg} / 4 \mathrm{~mL}$ ) was dropped onto the surface of the GCE and dried at $40{ }^{\circ} \mathrm{C}$ for $30 \mathrm{~min}$. $\mathrm{g}-\mathrm{C}_{3} \mathrm{~N}_{4} / \mathrm{GCE}$, PEDOT (BCP)/GCE and PEDOT/10 wt $\%$ g- $\mathrm{C}_{3} \mathrm{~N}_{4} / \mathrm{GCE}$ (obtained by different methods) were prepared by the same procedure.

\subsection{Characterization and instruments}

The FTIR spectra of the $\mathrm{g}-\mathrm{C}_{3} \mathrm{~N}_{4}$, PEDOT and PEDOT/g- $\mathrm{C}_{3} \mathrm{~N}_{4}$ composites were obtained using a BRUKER EQUINOX-55 Fourier transform infrared spectrometer (Bruker, Billerica, MA, USA) (frequency range 4000 to $500 \mathrm{~cm}^{-1}$ ). The UV-vis spectra of the samples were recorded on a UV-vis spectrophotometer (UV4802, Unico, Dayton, NJ, USA). The XRD patterns of the samples were conducted on a Bruker AXS D8 diffractometer with $\mathrm{Cu}-\mathrm{K} \alpha$ radiation $(\lambda=0.154 \mathrm{~nm})$; the scan range $(2 \theta)$ was $10^{\circ}$ to $80^{\circ}$. The morphology analysis of the $\mathrm{g}-\mathrm{C}_{3} \mathrm{~N}_{4}$, PEDOT and PEDOT/g- $\mathrm{C}_{3} \mathrm{~N}_{4}$ composites was obtained on a scanning electron microscope (JSM7610F Plus, JEOL, Japan, operating voltage, $5 \mathrm{kV}$ ) and transmission electron microscope (JEOL model 2100, JEOL Ltd., Tokyo, Japan). The elemental compositions of the samples were measured using energy-dispersive X-ray spectroscopy (EDS), which was conducted on a Leo 1430VP microscope (Carl Zeiss Inc., Oberkochen, Germany). The real samples were verified by atomic absorption spectrometry (AAS) (Shimadzu AA6300C, lead wavelength $283.3 \mathrm{~nm}$, lamp current $5.0 \mathrm{~mA}$; cadmium wavelength $228.8 \mathrm{~nm}$, lamp current $5.0 \mathrm{~mA}$; slit $0.4 \mathrm{~nm}$ ).

The electrochemical performances were investigated via a three-electrode system on an electrochemical workstation. (ChenHua, CHI660C, Instruments Co.). The modified GCEs were used as the working electrode, a platinum electrode was the counter electrode and a calomel electrode was the reference electrode. Cyclic voltammetry (CV) was performed in a mixture of $5.0 \mathrm{mM}\left[\mathrm{Fe}(\mathrm{CN})_{6}\right]^{3-/ 4-}$ and $0.1 \mathrm{M} \mathrm{KCl}$ at $50 \mathrm{mV} \mathrm{s}^{-1}$. Differential pulse voltammetry (DPV) was performed in $0.1 \mathrm{M} \mathrm{ABS}(\mathrm{pH}$ $=4.5$ ) with an incremental potential of $2 \mathrm{mV}$ from -1.2 to $-0.2 \mathrm{~V}$, with a pulse width of $50 \mathrm{~ms}$ and pulse period of $100 \mathrm{~ms}$.

\section{Results and discussion}

\subsection{FT-IR spectra}

Fig. 1 shows the FTIR spectra of $\mathrm{g}-\mathrm{C}_{3} \mathrm{~N}_{4}$, PEDOT (BCP) and the PEDOT/g- $\mathrm{C}_{3} \mathrm{~N}_{4}$ nanocomposites. In the spectrum of $\mathrm{g}-\mathrm{C}_{3} \mathrm{~N}_{4}$, the band at $813 \mathrm{~cm}^{-1}$ was identified as the bending vibration of the planar triazine ring mode. The weak peak appearing at $890 \mathrm{~cm}^{-1}$ can be attributed to the deformation mode of crosslinked heptazine. ${ }^{52}$ The stretching vibrations of $\mathrm{C}-\mathrm{N}$ and $\mathrm{C}=\mathrm{N}$
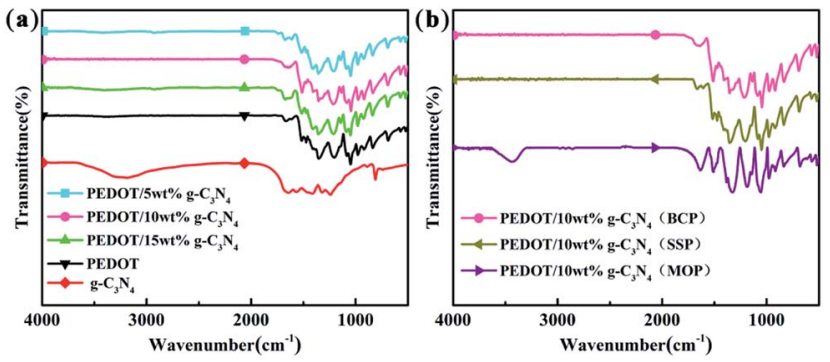

Fig. 1 FTIR spectra of (a) PEDOT (BCP) and PEDOT/g- $\mathrm{C}_{3} \mathrm{~N}_{4}$ nanocomposites with different weight percentages of $\mathrm{g}-\mathrm{C}_{3} \mathrm{~N}_{4}$ (b) PEDOT/ $10 \mathrm{wt} \% \mathrm{~g}-\mathrm{C}_{3} \mathrm{~N}_{4}$ prepared by different polymerization methods.

in the heterocyclic ring cause the characteristic peaks in the range of $1230-1650 \mathrm{~cm}^{-1} .53$ The wide vibration band appearing in the $3000-3500 \mathrm{~cm}^{-1}$ region is caused by the stretching vibration of the aromatic $\mathrm{N}-\mathrm{H}$ bond and the uncondensed amino group $\left(-\mathrm{NH}_{2}\right) .{ }^{54}$ For pure PEDOT (BCP), the characteristic peaks at 1515 and $1320 \mathrm{~cm}^{-1}$ are the typical $\mathrm{C}-\mathrm{C}$ asymmetric stretching vibration and inter-ring stretching vibration, respectively. The peaks at approximately 1209, 1139 and $1088 \mathrm{~cm}^{-1}$ are the $\mathrm{C}-\mathrm{O}-\mathrm{C}$ bending vibrations in the ethylenedioxy group. ${ }^{55}$ The bands at approximately 974, 918, 833, and $693 \mathrm{~cm}^{-1}$ are the characteristic absorption bands of the $\mathrm{C}-\mathrm{S}-\mathrm{C}$ bond in the thiophene ring. ${ }^{56}$

For the composites, as shown in Fig. 1(a) and (b), the main vibration bands are similar to those of PEDOT indicating that the successful incorporation of PEDOT component in composites. Fig. 1(a) and (b) show that the positions of the characteristic peaks for the PEDOT/10 wt $\%$ g- $\mathrm{C}_{3} \mathrm{~N}_{4}$ composites prepared by the SSP, MOP and BCP methods are basically identical. Furthermore, according to report, ${ }^{43}$ the intensity ratio of the vibration bands at approximately $1470 / 1515 \mathrm{~cm}^{-1}$ is indicative of the conjugation degree of the composites, with a smaller ratio indicating a higher degree of conjugation. Therefore, it is clear from Fig. 1(a) and (b) that PEDOT/10 wt\% $\mathrm{g}-\mathrm{C}_{3} \mathrm{~N}_{4}$ has a longer conjugated bond length. ${ }^{57}$ However, there are no characteristic peaks corresponding to $\mathrm{g}-\mathrm{C}_{3} \mathrm{~N}_{4}$ in the spectra of the PEDOT/g- $\mathrm{C}_{3} \mathrm{~N}_{4}$ composites, which may caused by overlapping of characteristic peak of PEDOT and $\mathrm{g}-\mathrm{C}_{3} \mathrm{~N}_{4}$. In addition, the $\mathrm{g}-\mathrm{C}_{3} \mathrm{~N}_{4}$ can also be enwrapped by PEDOT in some extent, consequently bring a decrease in peak intensity of $\mathrm{g}-\mathrm{C}_{3} \mathrm{~N}_{4}$.

\subsection{UV-vis spectra}

The UV-vis spectra of $\mathrm{g}-\mathrm{C}_{3} \mathrm{~N}_{4}$, PEDOT (BCP), and the PEDOT/g$\mathrm{C}_{3} \mathrm{~N}_{4}$ composites are presented in Fig. 2. It is clear from Fig. 2(a) that the UV-vis spectral peaks of $\mathrm{g}-\mathrm{C}_{3} \mathrm{~N}_{4}$ appears from 270 to $430 \mathrm{~nm}$, which are absorption peaks characteristics of carbon nitride. The absorption bands of PEDOT (BCP) at approximately 399,426 and $460 \mathrm{~nm}$ can be ascribed to different conjugation lengths, and they are assigned to the $\pi-\pi$ transition of the thiophene ring. ${ }^{58}$ Furthermore, the absorption peaks of PEDOT/ $\mathrm{g}-\mathrm{C}_{3} \mathrm{~N}_{4}(\mathrm{BCP})$ at 550, 600 and $667 \mathrm{~nm}$ are assigned to the polaron and/or bipolaron band, ${ }^{\mathbf{5 9 , 6 0}}$ which indicates a strong interaction between PEDOT and g- $\mathrm{C}_{3} \mathrm{~N}_{4}$. In Fig. 2(b), PEDOT/10 wt $\%$ g- $\mathrm{C}_{3} \mathrm{~N}_{4}$ 

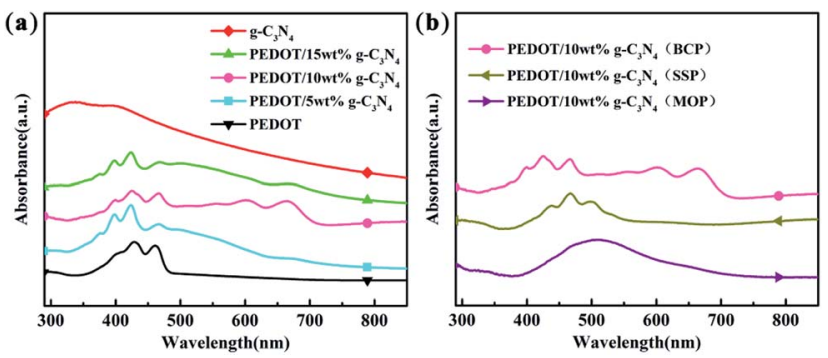

Fig. 2 UV-vis spectra of (a) PEDOT (BCP) and PEDOT/g- $\mathrm{C}_{3} \mathrm{~N}_{4}$ nanocomposites with different weight percentages of $\mathrm{g}-\mathrm{C}_{3} \mathrm{~N}_{4}$ (b) PEDOT/ $10 \mathrm{wt} \% \mathrm{~g}-\mathrm{C}_{3} \mathrm{~N}_{4}$ prepared by different polymerization methods.

(SSP) shows characteristic peaks at 437,465 and $498 \mathrm{~nm}$, which can also be assigned to the $\pi-\pi$ transition of the thiophene ring. Moreover, very weak absorption bands are also observed at $606 \mathrm{~nm}$, which indicates that the $\pi-\pi$ interaction between PEDOT and $\mathrm{g}-\mathrm{C}_{3} \mathrm{~N}_{4}$ is weak.

In the spectrum of PEDOT/10 wt\% $\mathrm{g}^{-\mathrm{C}_{3} \mathrm{~N}_{4}}$ (MOP), the absorption peak is located in the range of $400-600 \mathrm{~nm}$, which is in good agreement with that previously reported. ${ }^{45}$ By comparison, among composites, PEDOT/10 wt $\% \mathrm{~g}^{-} \mathrm{C}_{3} \mathrm{~N}_{4}$ (BCP) shows the highest $\pi-\pi$ interaction between PEDOT and $\mathrm{g}-\mathrm{C}_{3} \mathrm{~N}_{4}$, while it is the lowest in the case of PEDOT/10 wt $\% \mathrm{~g}^{-} \mathrm{C}_{3} \mathrm{~N}_{4}$ (SSP).

\subsection{XRD analysis}

Fig. 3 shows the XRD patterns of $g-\mathrm{C}_{3} \mathrm{~N}_{4}$, PEDOT (BCP) and the PEDOT/g- $\mathrm{C}_{3} \mathrm{~N}_{4}$ nanocomposites. In Fig. 3(a), the diffraction peaks of $\mathrm{g}-\mathrm{C}_{3} \mathrm{~N}_{4}$ can be seen at $27.3^{\circ}$ and $13.1^{\circ}$, which can be attributed to the (002) and (100) diffraction planes, respectively, of the graphite material. Among them, the stronger diffraction peak is assigned to the typical planes of graphitic structures, and the weaker peak at $13.1^{\circ}$ is attributed to the hole-to-hole arrays of the tri-s-triazine units. The XRD pattern of PEDOT (BCP) also shows two characteristic peaks at approximately $2 \theta=$ $26.2^{\circ}$ and $12.8^{\circ}$, which are due to intermolecular $\pi-\pi$ stacking. In the patterns of the PEDOT $/ \mathrm{g}-\mathrm{C}_{3} \mathrm{~N}_{4}$ composites (BCP), as the $\mathrm{g}$ $\mathrm{C}_{3} \mathrm{~N}_{4}$ content increases, the intensity of the diffraction peak at $12.8^{\circ}$ decreases, which is consistent with the increasing g- $\mathrm{C}_{3} \mathrm{~N}_{4}$. In Fig. 3(b), PEDOT/g- $\mathrm{C}_{3} \mathrm{~N}_{4}$ (SSP) shows the same characteristic peaks as PEDOT $/ \mathrm{g}-\mathrm{C}_{3} \mathrm{~N}_{4}$ (BCP). However, PEDOT $/ \mathrm{g}-\mathrm{C}_{3} \mathrm{~N}_{4}$ (MOP)
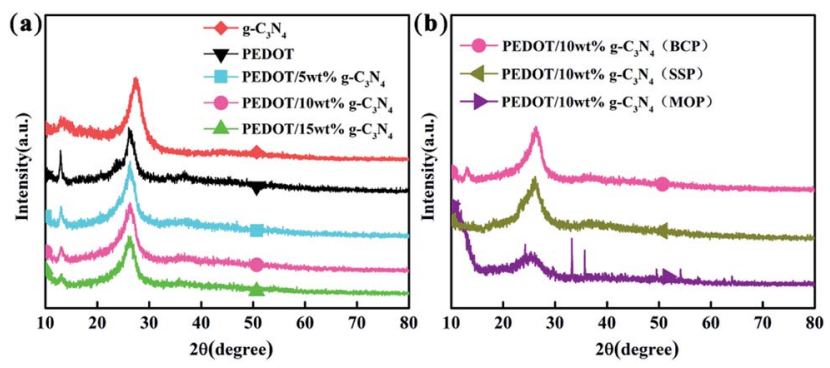

Fig. 3 The XRD patterns of FTIR spectra of (a) PEDOT (BCP) and $\mathrm{PEDOT} / \mathrm{g}-\mathrm{C}_{3} \mathrm{~N}_{4}$ nanocomposites with different weight percentages of g- $\mathrm{C}_{3} \mathrm{~N}_{4}$ (b) PEDOT/10 wt\% g- $\mathrm{C}_{3} \mathrm{~N}_{4}$ prepared by different polymerization methods. shows broader diffraction peaks at $26.2^{\circ}$ and sharp diffraction peaks at $2 \theta \approx 33^{\circ}, 35^{\circ}, 49^{\circ}$ and $54^{\circ}$ due to $\mathrm{FeCl}_{4}{ }^{-}$doping in the composite.

\subsection{EDS analysis}

Fig. 4 shows the EDS analysis of PEDOT (BCP) and the PEDOT/g$\mathrm{C}_{3} \mathrm{~N}_{4}$ composites on a silicon wafer. As shown in Fig. 4(a), the EDS spectrum of the pure PEDOT sample indicates the presence of $\mathrm{C}, \mathrm{S}, \mathrm{O}$, and $\mathrm{Br}$. After the addition of $\mathrm{g}-\mathrm{C}_{3} \mathrm{~N}_{4}$, some $\mathrm{N}$ was detected in the PEDOT/g- $\mathrm{C}_{3} \mathrm{~N}_{4}$ composites prepared by the three different methods. In Fig. 4(d), anhydrous ferric chloride was added as a catalyst in the reaction, which introduced $\mathrm{Fe}$ in the composites. Compared with PEDOT, the weight percentage of $\mathrm{N}$ in the composites increased with the addition of g- $\mathrm{C}_{3} \mathrm{~N}_{4}$.

\subsection{Morphology studies}

Fig. 5 and $\mathrm{S} 1 \uparrow$ show the SEM and TEM images of g- $\mathrm{C}_{3} \mathrm{~N}_{4}$, PEDOT (BCP), PEDOT/10 wt\% g- $\mathrm{C}_{3} \mathrm{~N}_{4}$ (BCP), PEDOT/10 wt $\%$ g- $\mathrm{C}_{3} \mathrm{~N}_{4}$ (SSP) and PEDOT $/ 10 \mathrm{wt} \% \mathrm{~g}-\mathrm{C}_{3} \mathrm{~N}_{4}$ (MOP), respectively. The pure PEDOT prepared by SSP presents a rule and plate-like structure, as shown in Fig. 5(b) and 6(b). After sonication for a period of time, due to $\pi-\pi$ stacking and aromatic electrostatic attraction, the DBEDOT monomer will be adsorbed onto the surface of flake g- $\mathrm{C}_{3} \mathrm{~N}_{4}$, which will allow the polymer to be uniform on the surface of $\mathrm{g}-\mathrm{C}_{3} \mathrm{~N}_{4}$.

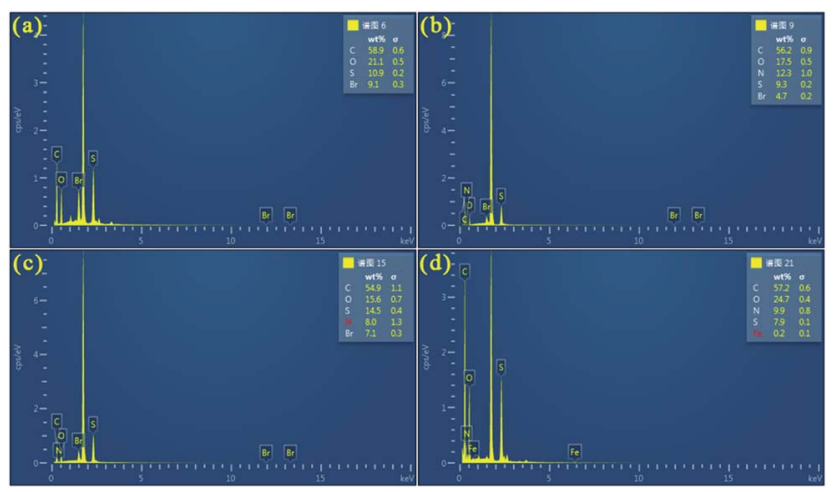

Fig. 4 EDS of (a) PEDOT (BCP), (b) PEDOT/10 wt\% g- $\mathrm{C}_{3} \mathrm{~N}_{4}$ (BCP), (c) PEDOT $/ 10 w t \% g-C_{3} N_{4}$ (SSP), (d) PEDOT/10 $w t \% g-C_{3} N_{4}$ (MOP).

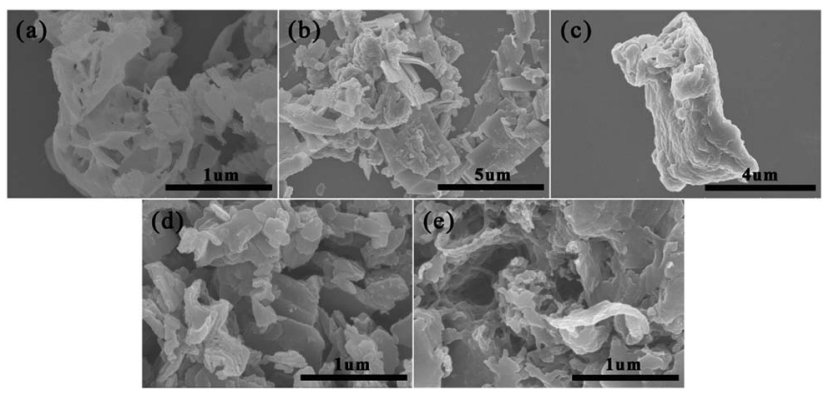

Fig. 5 SEM images of (a) $g-C_{3} N_{4}$ (b) PEDOT (BCP), (c) PEDOT/10 wt\% $\mathrm{g}-\mathrm{C}_{3} \mathrm{~N}_{4}$ (BCP), (d) PEDOT/10 wt\% g- $\mathrm{C}_{3} \mathrm{~N}_{4}$ (SSP), (e) PEDOT/10 wt\% g$\mathrm{C}_{3} \mathrm{~N}_{4}$ (MOP). 

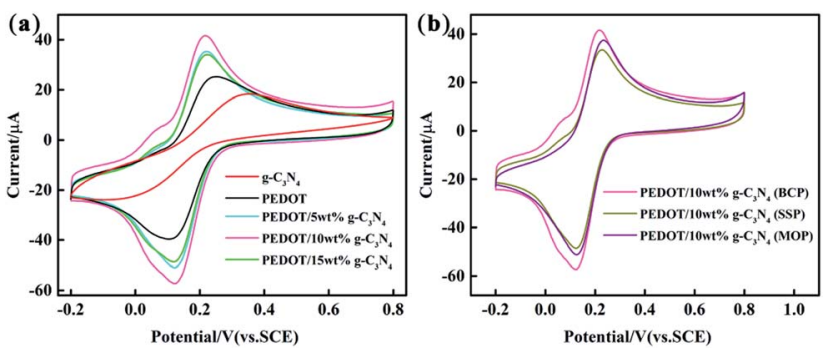

Fig. $6 \mathrm{CV}$ measured with $\mathrm{g}-\mathrm{C}_{3} \mathrm{~N}_{4}$, PEDOT (BCP), PEDOT/g- $\mathrm{C}_{3} \mathrm{~N}_{4}$ composite-modified glassy carbon electrode (GCE) in a solution of $5 \mathrm{mM} \mathrm{Fe}(\mathrm{CN})_{6}^{3-14-}$ containing $0.1 \mathrm{M} \mathrm{KCl}$. (a) $\mathrm{PEDOT} / \mathrm{g}-\mathrm{C}_{3} \mathrm{~N}_{4}$ nanocomposites with different weight percentages of $\mathrm{g}-\mathrm{C}_{3} \mathrm{~N}_{4}$ (b) PEDOT/ $10 \mathrm{wt} \% \mathrm{~g}-\mathrm{C}_{3} \mathrm{~N}_{4}$ prepared by different polymerization methods.

Therefore, the PEDOT/10 wt $\%$ g- $\mathrm{C}_{3} \mathrm{~N}_{4}$ composite prepared by BCP has a layered morphology, as shown in Fig. 5(c) and S1(c). $\dagger$ Furthermore, as shown in Fig. 5(d), (e) and S1(d), (e), $\uparrow$ the PEDOT $/ 10$ wt $\%$ g- $\mathrm{C}_{3} \mathrm{~N}_{4}$ composite prepared by SSP and MOP showed fragmented and irregular groups, respectively.

\subsection{Electrochemical characterization of PEDOT (BCP), g- $\mathrm{C}_{3} \mathrm{~N}_{4}$ and PEDOT/g- $\mathrm{C}_{3} \mathrm{~N}_{4}$ composites}

Cyclic voltammetry was performed with different modified GCEs in a mixture solution of $5 \mathrm{mM}\left[\mathrm{Fe}(\mathrm{CN})_{6}\right]^{3-/ 4-}$ and $0.1 \mathrm{M}$ $\mathrm{KCl}$ ( $50 \mathrm{~mL}, 1: 1$ by volume). As shown in Fig. 6, the anodic peak potentials are $0.38 \mathrm{~V}$ and $0.25 \mathrm{~V}$ for pure PEDOT (BCP) and g$\mathrm{C}_{3} \mathrm{~N}_{4}$ modified GCEs, respectively. And, the anodic peak current intensity is lower in $\mathrm{g}-\mathrm{C}_{3} \mathrm{~N}_{4}$-modified GCE than that of PEDOT (BCP) modified GCE. The main reason for this is that the lower electrical conductivity of $\mathrm{g}-\mathrm{C}_{3} \mathrm{~N}_{4}$ than that of PEDOT (BCP) can lead a low peak potential and current occurred in $\mathrm{g}-\mathrm{C}_{3} \mathrm{~N}_{4}$ modified GCE than that of PEDOT (BCP) modified GCE. ${ }^{27}$ After combination of $\mathrm{g}-\mathrm{C}_{3} \mathrm{~N}_{4}$ with PEDOT, the peak potential of samples shifted to low potential at about $0.22 \mathrm{~V}$ with high current intensity than that of PEDOT (BCP). All these results showed that the of PEDOT (BCP) and $\mathrm{g}-\mathrm{C}_{3} \mathrm{~N}_{4}$ cannot be used alone as a high sensitive materials for ions with their lower electrochemical activity than that of composites. However, the heterojunction of PEDOT (BCP) and $\mathrm{g}-\mathrm{C}_{3} \mathrm{~N}_{4}$ can bring an enhancement in electrochemical activity of electrode materials. According to previous report, although $\mathrm{g}-\mathrm{C}_{3} \mathrm{~N}_{4}$ is poor in electrical conductivity, it has fast charge transfer ability and large surface area with $\pi-\pi$ conjugation structure. ${ }^{61,62}$ The enhancement in electrochemical activity composites should be assigned to the strong $\pi-\pi$ interaction between PEDOT and $g-\mathrm{C}_{3} \mathrm{~N}_{4}$ by $\pi-$ $\pi$ stacking effect. And, the fast charge transfer ability of g- $\mathrm{C}_{3} \mathrm{~N}_{4}$ as well as the high electrical conductivity of PEDOT can cause a rapid electron transfer occurring at the interface of composite electrodes, which can promote the electrochemical performance of composite electrodes. As shown in Fig. 6(b), the PEDOT $/ 10 \mathrm{wt} \% \mathrm{~g}-\mathrm{C}_{3} \mathrm{~N}_{4}$ (BCP) composite-modified GCE exhibits the highest peak current than that of other composite/GCEs, which can be explained by the strong $\pi-\pi$ interaction between PEDOT and $\mathrm{g}-\mathrm{C}_{3} \mathrm{~N}_{4}$ in the composite prepared by BCP, while PEDOT/10 wt $\%$ g- $\mathrm{C}_{3} \mathrm{~N}_{4}$ (SSP) composite modified GCE exhibits the lowest peak current resulting from the low $\pi-\pi$ interaction between PEDOT and $\mathrm{g}-\mathrm{C}_{3} \mathrm{~N}_{4}$ in composite from SSP method.

Fig. S2 $\uparrow$ shows the DPV curves for $2.0 \mu \mathrm{M} \mathrm{Cd}^{2+}$ and $\mathrm{Pb}^{2+}$ in a $0.1 \mathrm{M}$ ABS $(\mathrm{pH}=4.5)$ solution with the different modified GCEs. As shown in Fig. S2, $\uparrow$ the distance between the characteristic peaks of $\mathrm{Cd}^{2+}$ and $\mathrm{Pb}^{2+}$ is sufficiently wide, and the peak positions of $\mathrm{Cd}^{2+}$ and $\mathrm{Pb}^{2+}$ are at approximately $-0.81 \mathrm{~V}$ and $-0.58 \mathrm{~V}$, respectively. As shown in Fig. $\mathrm{S} 2, \uparrow$ the $\mathrm{g}-\mathrm{C}_{3} \mathrm{~N}_{4}$ presents a similar electrocatalytic performance with that of PEDOT and PEDOT/10 wt $\%$ g- $\mathrm{C}_{3} \mathrm{~N}_{4}$ from SSP method. This can understood by the large number of nitrogen-containing groups in $\mathrm{g}-\mathrm{C}_{3} \mathrm{~N}_{4}$, which can coordinate with metal ions to enhance the electrocatalytic activity. ${ }^{28,63}$ The comparison also indicates that the composite from BCP method displayed a higher peak current than others. The reason for this can be that the plate-like morphology of PEDOT from the BCP method, which is beneficial for a uniform combination of PEDOT and $\mathrm{g}-\mathrm{C}_{3} \mathrm{~N}_{4}$ flakes, and the strong $\pi-\pi$ interaction between PEDOT and $g-\mathrm{C}_{3} \mathrm{~N}_{4}$, coordination effect of $\mathrm{g}-\mathrm{C}_{3} \mathrm{~N}_{4}$ with metal ions as well as the fast charge transfer ability and large surface of $\mathrm{g}-\mathrm{C}_{3} \mathrm{~N}_{4}$ can increase the synergetic effect of the components, which can also enhance the electrochemical properties of the composite. In the case of PEDOT $/ 10$ wt $\%$ g $-\mathrm{C}_{3} \mathrm{~N}_{4}$ from SSP and MOP methods, the inventible mixing of the inorganic and organic phase as well as low $\pi-\pi$ interaction between PEDOT and $g-\mathrm{C}_{3} \mathrm{~N}_{4}$ in SSP method is the negative effect for the electrocatalytic oxidation of metal ions, while iron ion doping MOP method can play negative for the electrocatalytic oxidation of metal ions. In summary, PEDOT/g- $\mathrm{C}_{3} \mathrm{~N}_{4}$ prepared by BCP not only effectively increases the electron transfer kinetics of the electrode surface but also avoids doping with iron ions. In addition, the interaction between the conjugated structure of PEDOT and flakes, such as g- $\mathrm{C}_{3} \mathrm{~N}_{4}$, through $\pi-\pi$ stacking allows strong adsorption of heavy metal ions. ${ }^{63}$

\subsection{Individual determination of $\mathrm{Cd}^{2+}$ and $\mathrm{Pb}^{2+}$}

To systematically study the performance difference among the composites prepared by three different methods, under optimized conditions, various modified GCEs were used for electrochemical determination of $\mathrm{Cd}^{2+}$ and $\mathrm{Pb}^{2+}$ in $0.1 \mathrm{M} \mathrm{ABS}(\mathrm{pH}=$ 4.5) by DPV. Fig. 7 and S3, S4 $\uparrow$ show the DPV responses of PEDOT $/ 10 w t \%$ g- $\mathrm{C}_{3} \mathrm{~N}_{4}$ (BCP), PEDOT/10 wt $\% \mathrm{~g}-\mathrm{C}_{3} \mathrm{~N}_{4}$ (SSP), and PEDOT/10 wt $\%$ g- $\mathrm{C}_{3} \mathrm{~N}_{4}$ (MOP) composite-modified GCEs
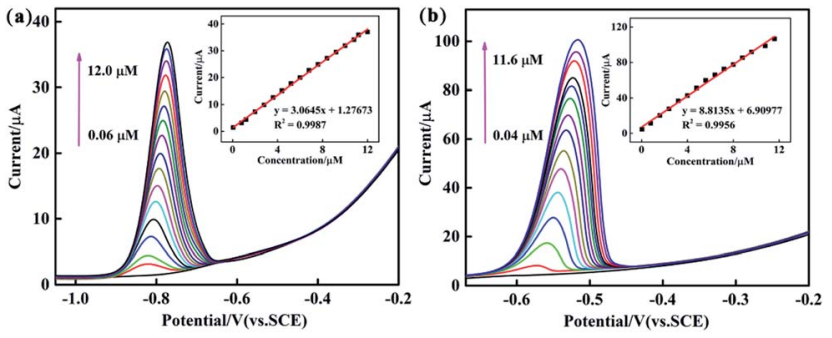

Fig. 7 DPV response of the PEDOT/10 $w t \% ~ g-C_{3} N_{4}$ (BCP) compositemodified GCE for the individual analysis of (a) $\mathrm{Cd}^{2+}$ (b) $\mathrm{Pb}^{2+}$. The inset shows their linear equations as well as correlation coefficient. 
Table 1 Performance of the PEDOT/10 wt\% g-C $\mathrm{N}_{4} / \mathrm{GCE}$ for individual determination of $\mathrm{Cd}^{2+}$ and $\mathrm{Pb}^{2+}$

\begin{tabular}{llllll}
\hline Methods & Analytes & Linear range $(\mu \mathrm{M})$ & Linear regression equation & $R^{2}$ & Detection limit $(\mu \mathrm{M})$ \\
\hline $\mathrm{BCP}$ & $\mathrm{Cd}^{2+}$ & $0.06-12.0$ & $y=3.0645 x+1.27673$ & 0.9987 & 0.0014 \\
& $\mathrm{~Pb}^{2+}$ & $0.04-11.6$ & $y=8.8135 x+6.90977$ & 0.9956 & 0.00421 \\
$\mathrm{SSP}$ & $\mathrm{Cd}^{2+}$ & $0.1-6.8$ & $y=0.63559 x-0.3114$ & 0.9821 & 0.0521 \\
& $\mathrm{~Pb}^{2+}$ & $0.1-6.0$ & $y=10.6259 x-1.4879$ & 0.9934 & 0.0263 \\
$\mathrm{MOP}$ & $\mathrm{Cd}^{2+}$ & $0.1-3.6$ & $y=1.6021 x+0.2147$ & 0.9923 & 0.0065 \\
& $\mathrm{~Pb}^{2+}$ & $0.1-2.8$ & $y=27.3213 x+5.1612$ & 0.9844 & 0.0637
\end{tabular}
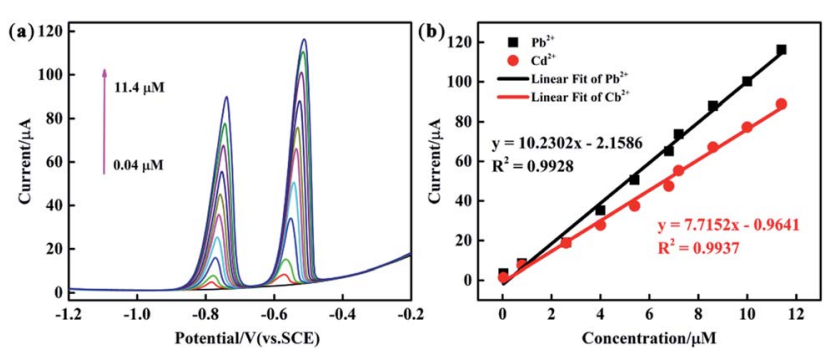

Fig. 8 (a) DPV response of the PEDOT/10 wt\% $\mathrm{g}-\mathrm{C}_{3} \mathrm{~N}_{4}$ (BCP) composite-modified GCE for the simultaneous analysis of $\mathrm{Cd}^{2+}$ and $\mathrm{Pb}^{2+}(\mathrm{b})$ the respective calibration curves of $\mathrm{Cd}^{2+}$ and $\mathrm{Pb}^{2+}$.

towards $\mathrm{Cd}^{2+}$ and $\mathrm{Pb}^{2+}$, and the inset shows their linear equations and correlation coefficients (Fig. 7 and $\mathrm{S} 3, \mathrm{~S} 4 \uparrow$ inset). As from the above results, PEDOT/10 $\mathrm{wt} \% \mathrm{~g}-\mathrm{C}_{3} \mathrm{~N}_{4}$ (BCP) exhibited detection limits of $0.0014 \mu \mathrm{M}$ and $0.0042 \mu \mathrm{M}$ with linear ranges of 0.06-12.0 $\mu \mathrm{M}$ and $0.04-11.6 \mu \mathrm{M}$ for $\mathrm{Cd}^{2+}$ and $\mathrm{Pb}^{2+}$, respectively. (Other detailed results are shown in Table 1). It is clear that the PEDOT/10 wt\% g- $\mathrm{C}_{3} \mathrm{~N}_{4}$ (BCP)/GCE shows a wide linear range and low detection limit, and the detection limit was lower than that of the WHO standard, illustrating that the PEDOT/ $10 \mathrm{wt} \% \mathrm{~g}-\mathrm{C}_{3} \mathrm{~N}_{4}$ prepared by $\mathrm{BCP}$ provides a large number of active sites, thereby increasing the adsorption of heavy metal ions.

\subsection{Simultaneous determination of $\mathrm{Cd}^{2+}$ and $\mathrm{Pb}^{2+}$}

The analytical performance of the PEDOT/10 wt\% g- $\mathrm{C}_{3} \mathrm{~N}_{4} / \mathrm{GCE}$ (BCP), PEDOT/10 wt\% g-C $\mathrm{N}_{3} / \mathrm{GCE}$ (SSP), and PEDOT/10 wt $\% \mathrm{~g}-$ $\mathrm{C}_{3} \mathrm{~N}_{4} / \mathrm{GCE}$ (MOP) was investigated through simultaneous determination of $\mathrm{Cd}^{2+}$ and $\mathrm{Pb}^{2+}$ in $0.1 \mathrm{M} \mathrm{ABS}(\mathrm{pH}=4.5)$. Fig. 8 and $\mathrm{S} 5, \mathrm{~S} 6 \dagger$ show the linear equations and correlation coefficients for each modified electrode. For simultaneous detection, there may be two factors affecting the performance results: the active sites on the modified electrode and the competitive effect between different ions. The PEDOT/10 wt\% $\mathrm{g}-\mathrm{C}_{3} \mathrm{~N}_{4}$ (BCP) exhibited the widest linear ranges of those tested with a linear range of 0.04-11.4 $\mu \mathrm{M}$ for $\mathrm{Cd}^{2+}$ and $\mathrm{Pb}^{2+}$ and detection limits of $0.00547 \mu \mathrm{M}$ and $0.00694 \mu \mathrm{M}$ for $\mathrm{Cd}^{2+}$ and $\mathrm{Pb}^{2+}$, respectively. (Other detailed results are shown in Table 2). This result indicates that the composite prepared by the BCP method has a larger number of active sites than the other two composites and no iron bonding.

\subsection{Real sample analysis}

To quantify $\mathrm{Cd}^{2+}$ and $\mathrm{Pb}^{2+}$ in real samples and estimate the applicability of PEDOT/10 wt\% g- $\mathrm{C}_{3} \mathrm{~N}_{4}$ (BCP), a standard addition method was carried out with a tap water sample. First, $0.1 \mathrm{M}$ ABS ( $\mathrm{pH}=4.5)$, which included certain amounts of tap water, was prepared. Subsequently, different amounts of $\mathrm{Cd}^{2+}$ and $\mathrm{Pb}^{2+}$ standard solutions were added to the testing system. The test sample was found by DPV and the recoveries of $\mathrm{Cd}^{2+}$ and $\mathrm{Pb}^{2+}$ were $96-103.5 \%$ and $96-101.7 \%$, respectively. The ion concentration of the test sample was verified by AAS and the recoveries of $\mathrm{Cd}^{2+}$ and $\mathrm{Pb}^{2+}$ were $89-98.5 \%$ and $92-106.6 \%$, respectively (Table 3 ). Based on the above results, the PEDOT/ $10 \mathrm{wt} \% \mathrm{~g}-\mathrm{C}_{3} \mathrm{~N}_{4}$ (BCP)/GCE has practical application for the determination of $\mathrm{Cd}^{2+}$ and $\mathrm{Pb}^{2+}$ in tap water samples with excellent sensitivity and recovery.

To compare with the SSP and MOP method composites, the results from electrochemical tests showed that the reliability and linear detection range of the composite from the bromine catalysed polymerization method were significantly improved, which can be related to the absence of iron bonding enhancing the absorption of $\mathrm{Cd}^{2+}$ and $\mathrm{Pb}^{2+}$. Moreover, the plate-like morphology of PEDOT from the $\mathrm{Br}_{2}$-catalysed polymerization method is beneficial for a uniform composition of PEDOT and

Table 2 Performance of the PEDOT/10 wt\% g- $\mathrm{C}_{3} \mathrm{~N}_{4} / \mathrm{GCE}$ for simultaneous determination of $\mathrm{Cd}^{2+} \mathrm{and}^{\mathrm{Pb}}{ }^{2+}$

\begin{tabular}{llllll}
\hline Methods & Analytes & Linear range $(\mu \mathrm{M})$ & Linear regression equation & $R^{2}$ & Detection limit $(\mu \mathrm{M})$ \\
\hline BCP & $\mathrm{Cd}^{2+}$ & $0.04-11.4$ & $y=7.7152 x-0.9641$ & 0.9937 & 0.0068 \\
& $\mathrm{~Pb}^{2+}$ & & $y=10.2302 x-2.1586$ & 0.9928 & 0.0079 \\
$\mathrm{SSP}$ & $\mathrm{Cd}^{2+}$ & $0.1-4.0$ & $y=1.5714 x+1.3715$ & 0.9927 & 0.0054 \\
& $\mathrm{~Pb}^{2+}$ & & $y=17.0702 x+2.4552$ & 0.9887 & 0.064 \\
$\mathrm{MOP}$ & $\mathrm{Cd}^{2+}$ & $0.1-2.8$ & $y=2.3403 x+1.4897$ & 0.9994 & 0.0011 \\
& $\mathrm{~Pb}^{2+}$ & & $y=21.9224 x+3.0524$ & 0.9911 & 0.0059
\end{tabular}


Table 3 Determination of $\mathrm{Cd}^{2+}$ and $\mathrm{Pb}^{2+}$ in tap water by PEDOT/ $10 \mathrm{wt} \% \mathrm{~g}-\mathrm{C}_{3} \mathrm{~N}_{4}$ (BCP)

\begin{tabular}{|c|c|c|c|c|c|c|c|c|c|c|}
\hline \multirow[b]{3}{*}{ No. } & \multirow{2}{*}{\multicolumn{2}{|c|}{$\begin{array}{l}\text { Added } \\
(\mu \mathrm{M})\end{array}$}} & \multicolumn{4}{|l|}{ DPV } & \multicolumn{4}{|l|}{ AAS } \\
\hline & & & \multicolumn{2}{|c|}{$\begin{array}{l}\text { Found } \\
(\mu \mathrm{M})\end{array}$} & \multicolumn{2}{|c|}{$\begin{array}{l}\text { Recovery } \\
(\%)\end{array}$} & \multicolumn{2}{|c|}{$\begin{array}{l}\text { Found } \\
(\mu \mathrm{M})\end{array}$} & \multicolumn{2}{|c|}{$\begin{array}{l}\text { Recovery } \\
(\%)\end{array}$} \\
\hline & $\mathrm{Cd}^{2+}$ & $\mathrm{Pb}^{2+}$ & $\mathrm{Cd}^{2+}$ & $\mathrm{Pb}^{2+}$ & $\mathrm{Cd}^{2+}$ & $\mathrm{Pb}^{2+}$ & $\mathrm{Cd}^{2+}$ & $\mathrm{Pb}^{2+}$ & $\mathrm{Cd}^{2+}$ & $\mathrm{Pb}^{2+}$ \\
\hline \multirow[t]{3}{*}{1} & 1 & 1 & 0.97 & 0.96 & 97 & 96 & 0.89 & 0.94 & 89 & 94 \\
\hline & 2 & 2 & 2.07 & 1.93 & 103.5 & 96.5 & 1.90 & 2.11 & 95 & 105.5 \\
\hline & 3 & 3 & 2.95 & 3.02 & 98.3 & 100.7 & 2.87 & 2.94 & 95.6 & 98 \\
\hline \multirow[t]{3}{*}{2} & 1 & 1 & 0.96 & 1.08 & 96 & 108 & 0.94 & 0.92 & 94 & 92 \\
\hline & 2 & 2 & 2.02 & 1.98 & 101 & 99 & 1.97 & 2.16 & 98.5 & 108 \\
\hline & 3 & 3 & 2.99 & 3.05 & 99.7 & 101.7 & 2.78 & 3.20 & 92.6 & 106.6 \\
\hline
\end{tabular}

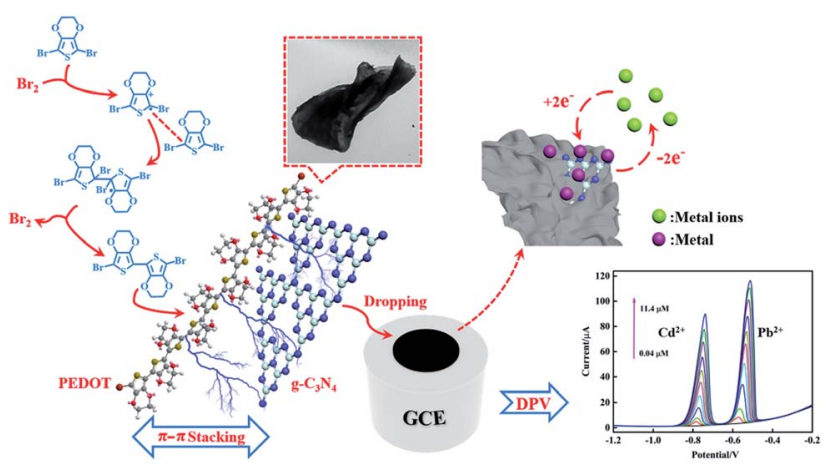

Fig. 9 Schematic illustration for the electrochemical determination of $\mathrm{Cd}^{2+}$ and $\mathrm{Pb}^{2+}$ by PEDOT/g- $\mathrm{C}_{3} \mathrm{~N}_{4}$ composite (BCP).

flakes, such as $\mathrm{g}-\mathrm{C}_{3} \mathrm{~N}_{4}$, which can increase the synergetic effect of the beneficial for a uniform composition of PEDOT and flakes, such as $\mathrm{g}-\mathrm{C}_{3} \mathrm{~N}_{4}$, which can increase the synergetic effect of the components and enhance the electrochemical properties of the composite by $\pi-\pi$ stacking interactions between PEDOT and $\mathrm{g}-\mathrm{C}_{3} \mathrm{~N}_{4}$ (Fig. 9).

\section{Conclusion}

In this paper, $\mathrm{PEDOT} / \mathrm{g}-\mathrm{C}_{3} \mathrm{~N}_{4}$ composites were prepared by different methods and applied for the electrochemical determination of $\mathrm{Cd}^{2+}$ and $\mathrm{Pb}^{2+}$. The results showed that the bromine catalysed polymerization (BCP) method is an effective way for preparation of PEDOT/g- $\mathrm{C}_{3} \mathrm{~N}_{4}$ composite. Among composites from different methods, PEDOT/10 wt\% g- $\mathrm{C}_{3} \mathrm{~N}_{4}$ (BCP) shows a highest $\pi-\pi$ interaction between PEDOT and $\mathrm{g}-\mathrm{C}_{3} \mathrm{~N}_{4}$, while it is the lowest in the case of PEDOT/10 $\mathrm{wt} \% \mathrm{~g}-\mathrm{C}_{3} \mathrm{~N}_{4}$ (SSP). In comparison with the SSP and MOP methods, the reliability and linear detection range of the composite from the $\mathrm{Br}_{2}$-catalysed polymerization method were significantly improved. All these results are originated from the plate-like morphology of PEDOT from the BCP method was beneficial for a uniform combination of PEDOT and $\mathrm{g}-\mathrm{C}_{3} \mathrm{~N}_{4}$ flakes, and the strong $\pi-\pi$ interaction between PEDOT and $\mathrm{g}-\mathrm{C}_{3} \mathrm{~N}_{4}$, coordination effect of $\mathrm{g}-\mathrm{C}_{3} \mathrm{~N}_{4}$ with metal ions as well as the fast charge transfer ability and large surface of $\mathrm{g}-\mathrm{C}_{3} \mathrm{~N}_{4}$, which could enhance the electrochemical properties of the composite from BCP by strong synergetic effect of the components. In the case of PEDOT/10 wt\% g- $\mathrm{C}_{3} \mathrm{~N}_{4}$ from SSP and MOP methods, the inventible mixing of the inorganic and organic phase as well as low $\pi-\pi$ interaction between PEDOT and $\mathrm{g}-\mathrm{C}_{3} \mathrm{~N}_{4}$ in SSP method is the negative effect for the electrocatalytic oxidation of metal ions, while iron ion doping MOP method can play negative for the electrocatalytic oxidation of metal ions. Furthermore, the PEDOT/10 wt $\% \mathrm{~g}-\mathrm{C}_{3} \mathrm{~N}_{4}$ (BCP) composite possesses a high sensitivity and low detection limit for $\mathrm{Cd}^{2+}$ and $\mathrm{Pb}^{2+}$, this will have potential applications in areas such as wastewater treatment and environmental protection.

\section{Conflicts of interest}

There are no conflicts to declare.

\section{Acknowledgements}

The authors acknowledge the research grant provided by National Natural Science Foundation of China (No. 21564014, No. 21865034).

\section{References}

1 H. Shirakawa, E. J. Louis, A. G. Macdiarmid, C. K. Chiang and A. J. Heeger, J. Chem. Soc., 1977, 16, 578-580.

2 Q. Zhou and G. Shi, J. Am. Chem. Soc., 2016, 138, 2868-2876.

3 S. C. Rasmussen, S. J. Evenson and C. B. McCausland, Chem. Commun., 2015, 51, 4528-4543.

4 M. Sassi, L. Mascheroni, R. Ruffo, M. M. Salamone, G. A. Pagani, C. M. Mari, G. D'Orazio, F. B. La and L. Beverina, Org. Lett., 2013, 15, 3502-3505.

5 J. E. Yoo and A. J. Bard, Proc. Natl. Acad. Sci. U. S. A., 2010, 107, 5712-5717.

6 L. Groenendaal, F. Jonas, D. Freitag, H. Pielartzik and J. R. Reynolds, Adv. Mater., 2000, 12, 481-494.

7 G. A. Sotzing, J. R. Reynolds and P. J. Steel, Adv. Mater., 1997, 9, 795-798.

8 I. F. Perepichka, B. Mohamed, E. Levillain, A. Marc Sallé and R. Jean, Chem. Mater., 2002, 14, 449-457.

9 F. Mouffouk and S. J. Higgins, Electrochem. Commun., 2006, 8, 15-20.

10 L. Yang, J. Zhang, F. Zhao and B. Zeng, J. Chromatogr. A, 2016, 1471, 80-86.

11 A. Tursun, A. Ahmat, J. Ruxangul, O. Yakupjan and Z. Yu, Nanoscale Res. Lett., 2014, 9, 89.

12 L. Tong, L. Jian, S. M. Boyer, L. A. Sonnenberg, M. T. Fox, D. Ji, J. Feng, W. E. Bernier and W. E. J. Jr, Electrochim. Acta, 2017, 224, 133-141.

13 W. Si, W. Lei, Z. Han, Q. Hao, Y. Zhang and M. Xia, Sens. Actuators, B, 2014, 199, 154-160.

14 K. Zhang, J. Xu, X. Duan, L. Lu, D. Hu, L. Zhang, T. Nie and K. B. Brown, Electrochim. Acta, 2014, 137, 518-525.

15 G. Maduraiveeran, M. Sasidharan and V. Ganesan, Biosens. Bioelectron., 2018, 103, 113. 
16 S. Duan and Y. Huang, J. Electroanal. Chem., 2017, 807, 253260.

17 J. Deep, V. K. Sangwan, L. J. Lauhon, T. J. Marks and M. C. Hersam, Chem. Soc. Rev., 2013, 42, 2824-2860.

18 W. A. Marmisollé and O. Azzaroni, Nanoscale, 2016, 8, 98909918.

19 S. Li, L. Wang, X. Zhang, H. Chai and Y. Huang, Sens. Actuators, B, 2018, 264, 312-319.

20 N. Wongkaew, M. Simsek, C. Griesche and A. J. Baeumner, Chem. Rev., 2019, 119, 120-194.

21 Y. Hu, Y. Huang, C. Tan, X. Zhang, Q. Lu, M. Sindoro, X. Huang, W. Huang, L. Wang and H. Zhang, Mater. Chem. Front., 2017, 1, 24-36.

22 Y. H. Wang, K. J. Huang and X. Wu, Biosens. Bioelectron., 2017, 97, 305-316.

23 A. F. Khan, B. Dac, C. W. Foster, G. C. Smith and C. E. Banks, Analyst, 2017, 142, 1756-1764.

24 G. H. Yang, J. J. Shi, S. Wang, W. W. Xiong, L. P. Jiang, C. Burda and J. J. Zhu, Chem. Commun., 2013, 49, 1075710759.

25 J. Tian, Q. Liu, A. M. Asiri, A. H. Qusti, A. O. Al-Youbi and X. Sun, Nanoscale, 2013, 5, 11604-11609.

26 Y. Zhang, X. Bo, A. Nsabimana, C. Luhana, G. Wang, H. Wang, M. Li and L. Guo, Biosens. Bioelectron., 2014, 53, 250-256.

27 J. Tian, Q. Liu, C. Ge, Z. Xing, A. M. Asiri, A. O. Al-Youbi and X. Sun, Nanoscale, 2013, 5, 8921-8924.

28 M. Sadhukhan and S. Barman, J. Mater. Chem. A, 2013, 1, 2752.

29 Y. Xu, W. Lei, J. Su, J. Hu, X. Yu, T. Zhou, Y. Yang, D. Mandler and Q. Hao, Electrochim. Acta, 2018, 259, 994-1003.

30 J. Zhang, Z. Zhu, J. Di, Y. Long, W. Li and Y. Tu, Electrochim. Acta, 2015, 186, 192-200.

31 H. Gu, T. Zhou and G. Shi, Talanta, 2015, 132, 871-876.

32 C. Li, J. Xu, Y. Wu, Y. Zhang, C. Zhang, W. Lei and Q. Hao, J. Electroanal. Chem., 2018, 824, 52-59.

33 X. Chen, X. Zhu, Y. Xiao and X. Yang, J. Electroanal. Chem., 2015, 743, 99-104.

34 Z. Xing, Z. Chen, X. Zong and L. Wang, Chem. Commun., 2014, 50, 6762-6764.

35 A. F. Diaz and K. K. Kanazawa,J. Chem. Soc., Chem. Commun., 1979, 14, 635.

36 K. Yoshino, S. Hayashi and R. Sugimoto, Jpn. J. Appl. Phys., 2014, 23, L899-L900.

37 J. Roncali, Chem. Rev., 1992, 92, 711-738.

38 M. Hong, D. F. Perepichka and W. Fred, Angew. Chem., 2010, 42, 658-661.

39 B. Baltasar and T. M. Swager, J. Am. Chem. Soc., 2012, 134, 18916-18919.
40 B. Aydogan, G. E. Gunbas, A. Durmus, L. Toppare and Y. Yagci, Macromolecules, 2010, 43, 101-106.

41 A. Patra, M. Bendikov and S. Chand, Acc. Chem. Res., 2014, 47, 1465-1474.

42 M. Pomerantz, B. Chaloner-Gill, L. O. Harding, J. J. Tseng and W. J. Pomerantz, ChemInform, 1993, 24, 1672-1673.

43 C. Wang, M. E. Benz, E. Legoff, J. L. Schindler, J. AllbrittonThomas, C. R. Kannewurf and M. G. Kanatzidis, Chem. Mater., 1994, 6, 40-49.

44 T. Yamamoto, K. Shiraishi, Y. Mahmut, I. Yamaguchi and L. Bert Groenendaal, Polymer, 2002, 43, 711-719.

45 J. M. Xu, H. S. O. Chan, S. C. Ng and T. S. Chung, Synth. Met., 2002, 132, 63-69.

46 M. H. Chahma, Synth. Met., 2005, 155, 474-479.

47 I. F. Perepichka, D. F. Perepichka and D. F. Perepichka, Mater. Today, 2009, 12, 54.

48 A. Patra, V. Agrawal, R. Bhargav, Shahjad, D. Bhardwaj, S. Chand, Y. Sheynin and M. Bendikov, Macromolecules, 2015, 48, 8760-8764.

49 N. Chidhambaram and K. Ravichandran, Mater. Lett., 2017, 207, 44-48.

50 F. Tranvan, S. Garreau, G. Louarn, G. Froyer and C. Chevrot, J. Mater. Chem., 2001, 11, 1378-1382.

51 A. Tursun, J. Ruxangul, C. Zhao, A. Tunsagul and N. Ismayil, Synth. Met., 2010, 160, 325-332.

52 M. J. Bojdys, M. Jens-Oliver, A. Markus and T. Arne, Chem.Eur. J., 2010, 14, 8177-8182.

53 S. Martha, A. Nashim and K. M. Parida, J. Mater. Chem. A, 2013, 1, 7816-7824.

54 X. Zhou, J. Bei, L. Li, P. Feng, H. Wang, Y. Hao and Y. Fang, J. Mater. Chem., 2012, 22, 17900-17905.

55 E. Eren, G. Celik, A. Uygun, J. Tabačiarová and M. Omastová, Synth. Met., 2012, 162, 1451-1458.

56 Y. Yang, Y. Jiang, J. Xu and J. Yu, Polymer, 2007, 48, 44594465.

57 Y. Furukawa, M. Akimoto and I. Harada, Synth. Met., 1987, 18, 151-156.

58 L. Yang, R. Jamal, F. Liu, Y. Wang and T. Abdiryim, RSC Adv., 2017, 7, 8625-8626.

59 T. Yamamoto, T. Shimizu and E. Kurokawa, React. Funct. Polym., 2000, 43, 79-84.

60 J. J. Apperloo, R. A. J. Janssen, M. M. Nielsen and K. Bechgaard, Adv. Mater., 2000, 12, 1594-1597.

61 X. Yuan, W. Qin, X. Lei, L. Sun, Q. Li, D. Li, H. Xu and D. Xia, Chemosphere, 2018, 205, 369-379.

62 Y. Zhang, Q. Li, Y. Long, J. Zou, Z. Song, C. Liu, L. Liu, F. Qi, B. Xu and Z. Chen, Appl. Catal., B, 2019, 254, 569-579.

63 Z. Guo, Y. Yuan, W. Hui, L. Gang and Z. Wang, Electrochim. Acta, 2016, 220, 267-275. 